\title{
Effect of Aporosa villosa Stem Ethanolic Extract on Adipogenesis in 3T3-L1 Adipocytes
}

\author{
Urarat Nanna', Linda Chularojmontri', Pholawat Tingpej', Rawiwun Kaewamatawong' ${ }^{2}$, Sudarat Homhual' \\ Wanwisa Suwannaloet ${ }^{3}$, Thanes Fuangfoo ${ }^{4}$ and Jarinyaporn Naowaboot ${ }^{1, *}$
}

\section{Urarat Nanna', Linda \\ Chularojmontri', Pholawat \\ Tingpej', Rawiwun \\ Kaewamatawong' ${ }^{2}$, Sudarat \\ Homhual ${ }^{2}$, Wanwisa \\ Suwannaloet ${ }^{3}$, Thanes Fuangfoo ${ }^{4}$ and Jarinyaporn Naowaboot ${ }^{1, *}$}

'Department of Preclinical Science, Faculty of Medicine, Thammasat University, Pathum Thani 12120, THAILAND.

${ }^{2}$ Faculty of Pharmaceutical Sciences, Ubon Ratchathani University, Ubon Ratchathani, 34190, THAILAND.

${ }^{3}$ Faculty of Medicine, Ubon Ratchathani University, Ubon Ratchathani, 34190, THAILAND.

${ }^{4}$ Department of Pharmacology, College of Pharmacy, Rangsit University, Pathum Thani 12120, THAILAND.

\section{Correspondence}

\section{Jarinyaporn Naowaboot}

Department of Preclinical Science, Faculty of Medicine, Thammasat University,

Pathum Thani 12120, THAILAND.

E-mail: naowaboot@yahoo.com

History

- Submission Date: 14-07-2021;

- Review completed: 06-08-2021;

- Accepted Date: 11-08-2021.

DOI : 10.5530/pj.2021.13.180

Article Available online http://www.phcogj.com/v13/i6

\section{Copyright}

(C) 2021 Phcogj.Com. This is an open access article distributed under the terms of the Creative Commons Attribution 4.0 International license.

\begin{abstract}
Background: An excessive fat accumulation is related to development of obesity. Obesity is associated with the induction of insulin resistance and diabetes mellitus conditions. Aporosa villosa is a plant that found in the Northern and Northeastern region of Thailand. Objective: The present study used 3T3-L1 adipocytes for investigating the effect of Aporosa villosa stem ethanolic extract (AS) on adipogenesis. Materials and Methods: 3T3-L1 adipocytes were used for measuring the cytotoxicity of AS at a concentration range of 3-100 $\mu \mathrm{g} / \mathrm{mL}$. After adipocyte cells treated with AS $(3-100 \mu \mathrm{g} / \mathrm{mL})$ for 8 days, the lipid accumulation was detected by Oil Red $\mathrm{O}$ staining and adipogenic gene expression were determined by quantitative real-time PCR. Results: AS extracts $(3-100 \mu \mathrm{g} / \mathrm{mL})$ did not show cytotoxicity on cell proliferation. After 8 days of treating 3T3-L1 adipocytes with AS at doses of $3,10,30$ and $100 \mu \mathrm{g} / \mathrm{mL}$, the lipid droplets were reduced as compared to non-treated cells. Furthermore, the adipogenic genes were measured. The regulators of adipogenesis, CCAAT/enhancer-binding protein a (C/EBPa), peroxisome proliferatoractivated receptor $\mathrm{y}$ (PPARY) and sterol regulatory element binding protein 1c (SREBP1c) were found decreasing in AS extracts. The downstream target genes of these regulators cluster of differentiation (CD) 36, fatty acid synthase (FAS) and lipoprotein lipase (LPL) were also reduced by AS treatments. Conclusion: These findings indicate that AS extract has an inhibitory activity on adipogenesis in 3T3-L1 adipocytes via suppressing C/EBPa, PPARy and SREBP1C.

Key words: Aporosa villosa; Adipogenesis; Obesity.
\end{abstract}

\section{INTRODUCTION}

Obesity is responsible for the development of many diseases including hypertension, type 2 diabetes mellitus and atherosclerosis. ${ }^{1}$ Adipogenesis is the state of excess fat accumulation in adipocytes during the preadipocyte differentiation process ${ }^{2}$, and there is a study showing that increased adipocyte number related to obesity. ${ }^{3}$ Thus, the regulation of adipocyte number may be helpful for people who are obese. Several transcriptional factor genes such as CCAAT/enhancer-binding protein a $(\mathrm{C} / \mathrm{EBP} \alpha)$, peroxisome proliferator-activated receptor $\gamma($ PPAR $\gamma)$ and sterol regulatory element binding protein 1c (SREBP1c) are associated with the adipogenesis process. ${ }^{4} \mathrm{C} / \mathrm{EBP} \alpha$ and $\mathrm{PPAR} \gamma$ participate in a modulation of downstream lipogenic genes such as acetyl-CoA carboxylase (ACC), adipocyte fatty acid-binding protein 2 (aP2), cluster of differentiation (CD) 36, fatty acid synthase (FAS) and lipoprotein lipase (LPL). ${ }^{5}$

Aporosa villosa is a plant that found in the Northern and Northeastern region of Thailand. It is used as a traditional medicine in some areas of Thailand, such as Ubon Ratchathani, for treating jaundice. However, this plant has limited pharmacological data. As obesity is an important condition that associated with the progression of several diseases, any novel substance or medicine, especially from natural sources, that can tackle this problem would become beneficial. Therefore, the present study interested to investigate whether Aporosa villosa extract has an anti-obesity action.
The 3T3-L1 adipocyte cells were used as a model for determination of Aporosa villosa stem ethanolic extract on adipogenesis process. This study may provide supportive data for future study in animal and human models.

\section{MATERIALS AND METHODS}

\section{Chemicals and reagents}

Dulbecco's modified Eagle's medium (DMEM) with $4.5 \mathrm{~g} / \mathrm{L}$ glucose, sodium pyruvate and L-glutamine were obtained from Corning (Glendale, AZ, USA). Bovine calf serum (BCS), fetal bovine serum (FBS) were purchased from Gibco BRL (Grand Island, NY, USA). 3T3-L1 adipocyte (ATCC CL-173) was purchased from American Type Culture Collection (Manassas, VA, USA). TRIzol reagent was obtained from Invitrogen (Carlsbad, CA, USA). High Capacity cDNA Reverse Transcription Kit was purchased from Applied Biosystems (Foster City, CA, USA). LightCycler ${ }^{\circledR} 480$ SYBR Green I Master was purchased from Roche Molecular Systems (Pleasanton, CA, USA). Other chemicals were obtained from Sigma-Aldrich (St. Louise, MO, USA).

\section{Plant materials}

Aporosa villosa stem (AS) was collected from Ubon Ratchanthani. The identification (voucher specimen: AV-UBUPH00624) was approved by Faculty of Pharmaceutical Sciences, Ubon Ratchathani University.

The plant was dried and extracted with $95 \%$ ethanol by maceration ( $48 \mathrm{~h} \times 3$ times) at room temperature.

Cite this article: Nanna U, Chularojmontri L, Tingpej $P$, Kaewamatawong R, Homhual S, Suwannaloet W, et al. Effect of Aporosa villosa Stem Ethanolic Extract on Adipogenesis in 3T3L1 Adipocytes. Pharmacogn J. 2021;13(6): 1422-1427. 
The extracts were evaporated under reduced pressure to obtain the dry extracts. The yields of the dry powder were $8.22 \%$.

\section{Phytochemical screening}

The crude ethanolic extracts of AS were tested for the presence of phenolic contents by using high-performance liquid chromatography with diode array detection and mass spectrometry detector (HPLCDAD/MSD) method. ${ }^{6}$ Caffeic acid, catechin, courmaric acid, ferulic acid, gallic acid, protocatechuic acid, quercetin, rutin, sinapic acid and vanillic acid were used as phenolic standards.

\section{T3-L1 adipocyte culture}

The experiments of 3T3-L1 adipocytes were approved by the Thammasat University Institutional Biosafety Committee (TU-IBC 030/2562). The preadipocytes were plated in 24 -well plates $\left(2 \times 10^{5} \mathrm{cells} /\right.$ well $)$, cultured in DMEM with $10 \% \mathrm{BCS}$, penicillin and streptomycin at $37^{\circ} \mathrm{C}$ in $5 \%$ $\mathrm{CO}_{2}$. After 2 days of cell confluence, the induction of cell differentiation was started by incubating in DMEM/10\% FBS/penicillin/streptomycin with dexamethasone, 3-isobutyl-1-methylxanthine (IBMX) and insulin for $48 \mathrm{~h}$. Then, cells were maintained and re-fed every 2 days with DMEM/10\% FBS/penicillin/streptomycin/insulin. To determine the effect of AS on adipocyte differentiation, the cells were treated with AS at a concentration range of $3-100 \mu \mathrm{g} / \mathrm{mL}$ compared with the cells treated with dimethyl sulfoxide (DMSO) as a control group. Treatments of AS were started from the first day of the induction of cell differentiation (day 0 ) to the end of the experiment on day 8 . Three independent experiments were performed, each in triplicate.

\section{Oil Red O staining}

At the end of the experimental period, cells were fixed with $10 \%$ formalin for $1 \mathrm{~h}$ and washed 3 times with phosphate-buffered saline (PBS). Then, cells were stained with $0.6 \%$ Oil Red O solution for $1 \mathrm{~h}$ and washed again with PBS 3 times. The stained cells were photographed by Primovert (Carl Zeiss, NY, USA) at $\times 200$ magnification. After that, the stained Oil Red $\mathrm{O}$ was eluted with isopropanol and quantified by measuring absorbance at $540 \mathrm{~nm}$.

\section{Cell viability assay}

The 3T3-L1 cells $\left(1 \times 10^{4}\right.$ cells/well $)$ were plated into a 96-well plate and treated with serial dilutions of AS $(0-100 \mu \mathrm{g} / \mathrm{mL})$. After AS incubation for $48 \mathrm{~h}$, the cell viability was measured with 3-(4,5-dimethylthiazole-2yl)-2,5-diphenyltetrazolium bromide (MTT) solution. The absorbance of the sample was determined at $570 \mathrm{~nm}$. ${ }^{7}$ Three independent experiments were performed, each in triplicate.

\section{Measurement of quantitative real-time PCR}

Total RNA of 3T3-L1 cells was extracted using TRIzol reagent and reverse transcribed into cDNA using the High Capacity cDNA Reverse Transcription Kit. The SYBR Green-based quantitative real-time PCR was performed using a LightCycler ${ }^{\circledR} 480$ Instrument II (Roche Molecular Systems, Pleasanton, CA, USA). The primer sequences were mouse C/EBPa (Fwd: 5'-TGCCTATGAGCACTTCACAA-3', Rev: 5'-AACTCCAGCACCTTCTGTTG-3'), mouse PPAR $\gamma$ (Fwd: 5'-TGGGAACCTGGAAGC TTGTCTC-3', Rev: 5'TGTGGTAAAGGG CTTGATGT-3'), mouse SREBP1c (Fwd: 5'-GGGCTCTGCTGGACCAC-3', Rev: 5'-TGGCCTTGTCAATGGAACTG-3'), mouse CD36 (Fwd: 5'-TCTGAAGAGACCTTACATTGTACCTA-3', Rev: 5'-CAATCCCAAGTAAGGCCATC-3'), mouse FAS (Fwd: 5'-GCACCTATGGCGAGGACTT-3', Rev: 5'-ATGGATGATGTTGATGATGGA-3'), mouse LPL (Fwd: 5'-GGCCAGATTCATCAACTGGAT-3', Rev: 5'-GCTCCAAGGCTGTACCCTAAG-3') and mouse GAPDH (Fwd: 5'-CTGGAGAAACCTGCCAAGTA-3', Rev: 5'-AGTGGGAGTTGC TGTTGAAG-3'). Relative expressions were calculated with normalization to GAPDH with the formula $2^{-\Delta \Delta \mathrm{Ct}}$.

\section{Statistical analysis}

Data were expressed as mean \pm SEM. One-way analysis of variance (ANOVA) followed by Tukey's post-hoc test (Systat version 4.0, CA, USA) were used for investigating the significance difference among experimental groups. A statistical significance was set at $P<0.05$.

\section{RESULTS}

\section{Contents of phenolic compounds}

Contents of phenolics were found in AS extract as shown in Table 1. The three main phenolics found in AS were rutin $(199.20 \mu \mathrm{g} / \mathrm{g})$, vanillic acid $(106.91 \mu \mathrm{g} / \mathrm{g})$ and catechin $(98.60 \mu \mathrm{g} / \mathrm{g})$.

\section{Lipid accumulation}

At day 8 of AS incubation, the microscopic observations of the Oil Red O staining showed that the AS at $3-100 \mu \mathrm{g} / \mathrm{mL}$ could inhibit lipid accumulation as compared to the untreated adipocyte group (Figure 1A). The absorbance value revealed that the lipid accumulation in 3T3L1 adipocytes was significantly reduced by AS extracts $(3-100 \mu \mathrm{g} / \mathrm{mL})$ compared with the untreated adipocyte group (Figure 1B). Moreover, the inhibition of lipid accumulation of AS extracts did not cause cytotoxicity (Figure 1C).

\section{Adipogenic gene expression}

In comparison with the untreated adipocyte group, AS extracts (10$100 \mu \mathrm{g} / \mathrm{mL}$ ) significantly decreased the gene expressions of PPAR $\gamma$ and $\mathrm{C} / \mathrm{EBPa}$ (Figure $2 \mathrm{~A}$ and $2 \mathrm{~B}$ ). SREBP1c was also inhibited by AS (3-100 $\mu \mathrm{g} / \mathrm{mL}$ ) (Figure 2C). Moreover, the AS extracts $(3-100 \mu \mathrm{g} / \mathrm{mL}$ ) significantly reduced the level of CD36, FAS and LPL genes, compared with untreated adipocyte group (Figure 2D, 2E and 2F).

\section{DISCUSSION/CONCLUSION}

Obesity is a metabolic syndrome that is characterized by the excessive fat accumulation in adipose tissue. ${ }^{8}$ The present study investigated the effect of Aporosa villosa stem ethanolic extract in 3T3-L1 adipocytes. AS extracts $(3-100 \mu \mathrm{g} / \mathrm{mL})$ were able to suppress lipid accumulation and adipogenic gene expressions in 3T3-L1 adipocytes model. Thus, inhibition of excessive lipid storage in adipocytes may have a positive effect in preventing obesity.

There are several stages in processing adipogenesis from preadipocytes to differentiated mature adipocytes. ${ }^{9}$ In this study, AS $(3-100 \mu \mathrm{g} / \mathrm{mL})$ could inhibit lipid storage without showing cytotoxicity in adipocyte cells. There is a report indicating that the transcription factors $\mathrm{C} / \mathrm{EBP}$, PPAR $\gamma$ and SREBP1c are key regulators for the differentiation of preadipocytes to mature adipocytes. ${ }^{5} \mathrm{PAR} \gamma$ is involved in the late stage of adipocytes differentiation, and its absence can block lipid droplet formation..$^{10-11}$ The present result showed that AS at the concentration of 10,30 and $100 \mu \mathrm{g} / \mathrm{mL}$ could inhibit PPAR $\gamma$ gene in 3T3-L1 cells. It has been reported that C/EBPs and SREBPs are associated with regulating early stage of adipocyte differentiation process. ${ }^{12}$ Thus, the

\section{Table 1: Phenolic contents of AS.}

\begin{tabular}{ll}
\hline Phenolic compound contents & $\mu \mathrm{g} / \mathrm{g}$ \\
\hline Gallic acid & 3.14 \\
Protocatechuic acid & Not detectable \\
Vanillic acid & 106.91 \\
Caffeic acid & Not detectable \\
Courmaric acid & 13.67 \\
Ferulic acid & 6.97 \\
Sinapic acid & 20.82 \\
Catechin & 98.60 \\
Rutin & 199.20 \\
Quercetin & 10.81
\end{tabular}



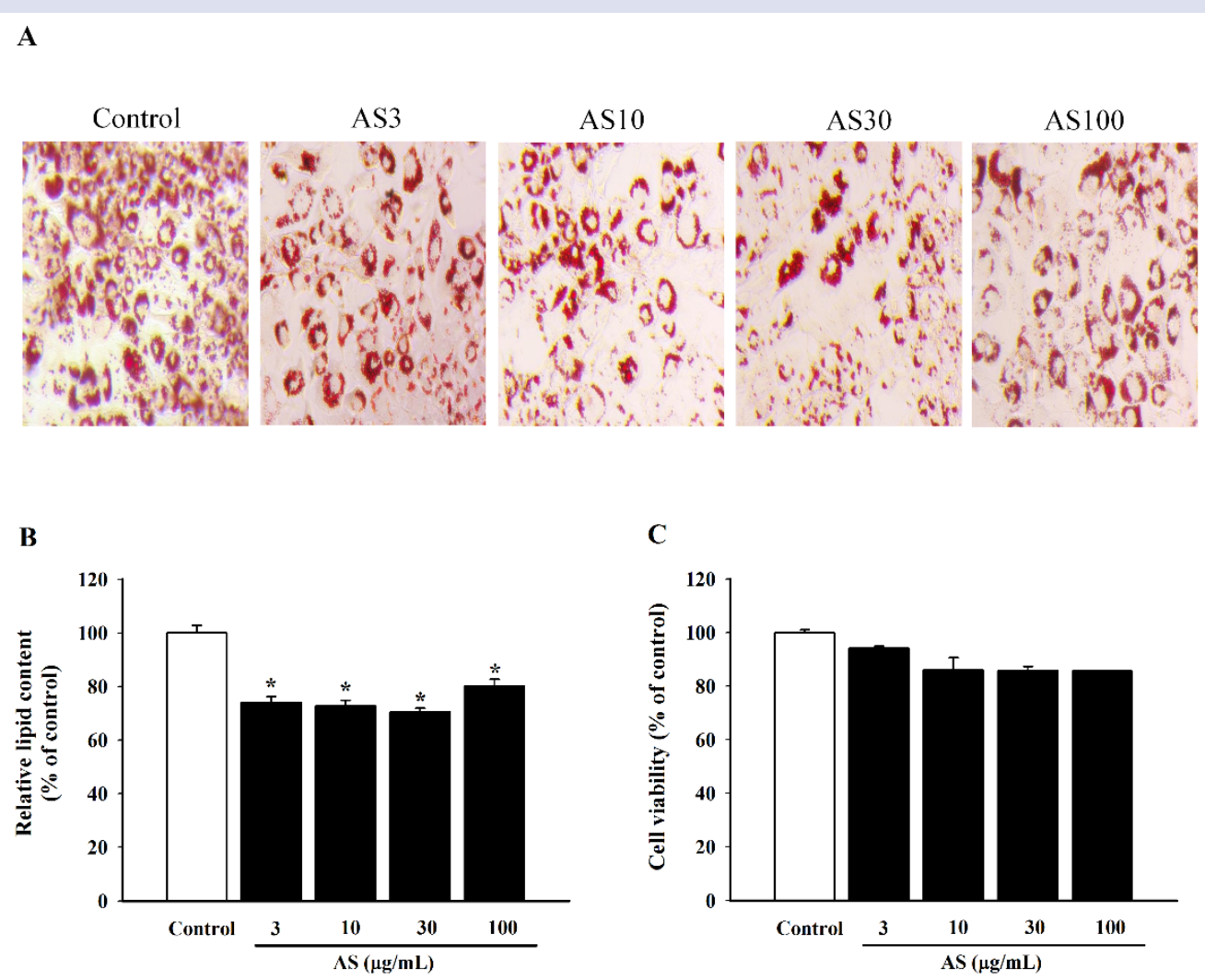

Figure 1: Effect of AS on lipid accumulation in 3T3-L1 adipocyte cells. At day 8 of treatment with 3-100 $\mu \mathrm{g} / \mathrm{mL} \mathrm{AS,} \mathrm{the} \mathrm{adipocyte}$ cells were stained with Oil Red O (A). Quantification of the lipid accumulation was based on the OD values at $540 \mathrm{~nm}$ of destained Oil Red $O$ from the adipocytes (B) and cell viability (C). Values are expressed as mean $\pm \operatorname{SEM}(n=3) .{ }^{*} P<0.05$ vs. the control group (untreated adipocyte cells). AS: Aporosa villosa stem ethanolic extract.

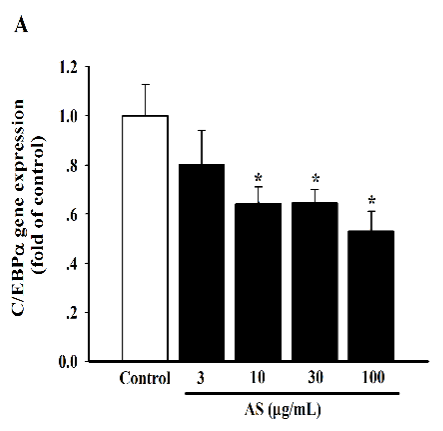

D

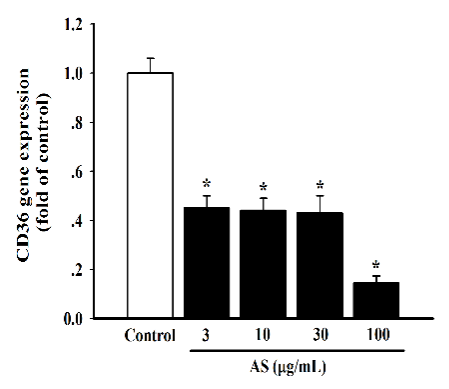

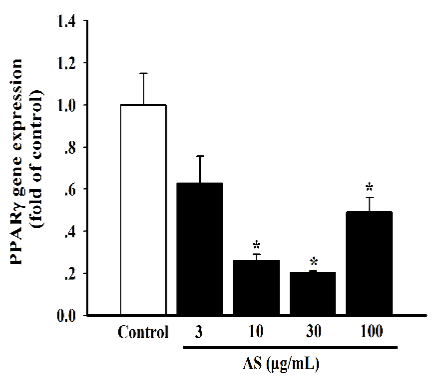

E

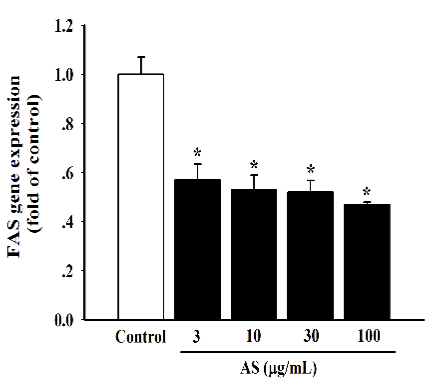

$\mathrm{C}$

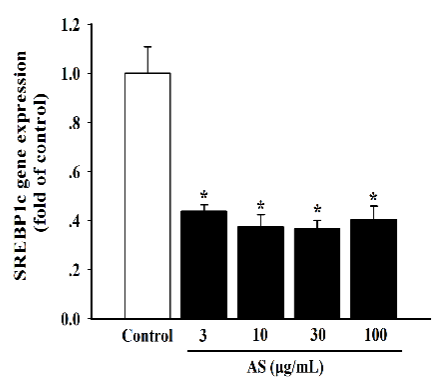

F

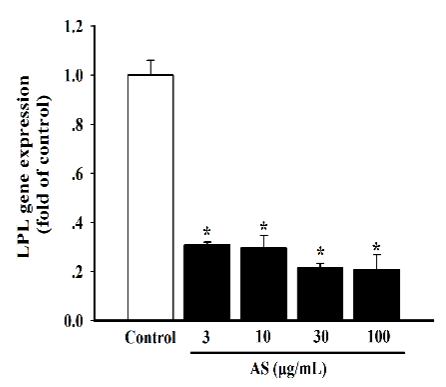

Figure 2: Effect of $A S$ on the expression of the adipogenic gene expressions of C/EBPa (A), PPARY (B), SREBP1C (C), CD36 (D), FAS $(E)$ and LPL (F) in 3T3-L1 adipocyte cells. Values are expressed as mean \pm SEM $(n=3)$. ${ }^{*} P<0.05$ vs. the control group (untreated adipocyte cells). AS: Aporosa villosa stem ethanolic extract. 
gene expressions of C/EBPa and SREBP1c were investigated in this study. The results showed that the AS treatment could reduce both genes in 3T3-L1 cells. These data demonstrated that AS treatment could inhibit the expression of transcription factor genes regulating adipogenesis.

The major transcription factors C/EBPa, PPAR $\gamma$ and SREBP1c involving in adipogenesis process regulate the adipocyte-specific markers such as LPL, FAS and CD $36 .{ }^{5}$ LPL is a major lipid synthesis enzyme which hydrolyzes lipoproteins from chylomicrons to free triglyceride in serum. ${ }^{13}$ Overexpression of LPL is related to the initiation of lipid accumulation..$^{14}$ FAS is also a lipid synthesis enzyme. It can induce fatty acid synthesis and lipid accumulation. ${ }^{15} \mathrm{CD} 36$ plays a role in adipocyte cholesterol and adipogenesis metabolism. ${ }^{16-17}$ Deficiency of CD36 could reduce the size and differentiation of adipocyte, and lipid accumulation in mice. ${ }^{18}$ This study showed that AS extracts could decrease expression of these aforementioned genes. We speculate that AS inhibited the expressions of C/EBPa, PPAR $\gamma$ and SREBP1c genes, resulting in the suppression of the adipocyte-specific markers CD36, FAS and LPL genes in 3T3-L1 adipocytes.

Aporosa villosa is a plant that found in the Northern and Northeastern region of Thailand. Although it has been used in regional traditional medicinal practices, its systematic pharmacological data is limited. Generally, phenolic compounds widely found in plants possess antioxidant and anti-obesity activities. ${ }^{19}$ In the present study, the AS extract was found to contain various phenolics, especially rutin, vanillic acid and catechin. These three main compounds have been previously reported to have an anti-obesity effect. ${ }^{19-21}$ It is thus likely that these main phenolic compounds in the AS extract play a role in suppressing adipogenesis process in 3T3-L1 adipocytes by regulating C/EBPs/ PPAR $\gamma /$ SREBP1c signaling pathways.

In conclusion, this study shows the effect of AS on adipocyte differentiation and lipid accumulation. AS extract can inhibit adipogenesis process by decreasing the lipid accumulation and suppressing the expression of C/EBPa, PPAR $\gamma$ and SREBP1c genes and their downstream target genes CD36, FAS and LPL. Overall, these results suggest that AS has an anti-adipogenic activity in the 3T3-L1 adipocyte model, which implies that it may have potential as an antiobesity agent.

\section{ACKNOWLEDGEMENTS}

This study was supported by Thammasat University Research Fund (Contract No.TUFT 027/2563).

\section{CONFLICTS OF INTEREST}

None.

\section{REFERENCES}

1. Wang S, Moustaid-Moussa N, Chen LX, Mo HB, Shastri A, Su R, et al. Novel insights of dietary polyphenols and obesity. Journal of Nutritional Biochemistry. 2014;25(1):1-18

2. Ghaben $A L$, Scherer PE. Adipogenesis and metabolic health. Nature Reviews Molecular Cell Biology. 2019;20(4):242-58.10.1038/ s41580-018-0093-z.

3. Kim EJ, Jung SN, Son KH, Kim SR, HaTY, Park MG, et al. Antidiabetes and antiobesity effect of cryptotanshinone via activation of AMPactivated protein kinase. Mol Pharmacol. 2007;72(1):62-72

4. Choi YR, Shim J, Kim MJ. Genistin: A Novel Potent Anti-Adipogenic and Anti-Lipogenic Agent. Molecules. 2020;25(9):2042

5. Farmer SR. Transcriptional control of adipocyte formation. Cell metabolism. 2006;4(4):263-73.10.1016/j.cmet.2006.07.001.
6. Duangjai A, Limpeanchob N, Trisat K, Amornlerdpison D. Spirogyra neglecta inhibits the absorption and synthesis of cholesterol in vitro. Integr Med Res. 2016;5(4):301-8.10.1016/j.imr.2016.08.004.

7. HWANG JS, LEE SB, CHOI M-J, KIM JT, SEO HG. Anti-adipogenic effect of a turmeric extract-loaded nanoemulsion in 3T3-L1 preadipocytes and high fat diet-fed mice. Food Science and Technology. 2019;39:439-47

8. Tandon P, Wafer R, Minchin JEN. Adipose morphology and metabolic disease. The Journal of Experimental Biology. 2018;221(Suppl 1):jeb164970.10.1242/jeb. 164970.

9. Hu Y-C, Zhang Z, Shi W-G, Mi T-Y, Zhou L-X, Huang N, et al. 2',4'-Dihydroxy-6'-methoxy-3',5'-dimethylchalcone Promoted Glucose Uptake and Imposed a Paradoxical Effect on Adipocyte Differentiation in 3T3-L1 Cells. J Agr Food Chem. 2014;62(8):1898904.10.1021/jf405368q.

10. Pratheeshkumar P, Kuttan G. Effect of vernolide-A, a sesquiterpene lactone from Vernonia cinerea L., on cell-mediated immune response in B16F-10 metastatic melanoma-bearing mice. Immunopharmacology Immunotoxicology. 2011;33(3):5338.10.3109/08923973.2010.547501.

11. Prazienkova $\mathrm{V}$, Holubova M, Pelantova H, Buganova M, Pirnik Z, Mikulaskova B, et al. Impact of novel palmitoylated prolactinreleasing peptide analogs on metabolic changes in mice with dietinduced obesity. Plos One. 2017;12(8):e0183449

12. Lee J-H, Kang HS, Park HY, Moon Y-A, KangYN, Oh B-C, et al. PPARadependent Insig2a overexpression inhibits SREBP-1c processing during fasting. Scientific Reports. 2017;7(1):9958.10.1038/s41598017-10523-7.

13. de Sa PM, Richard AJ, Hang H, Stephens JM. Transcriptional Regulation of Adipogenesis. Compr Physiol. 2017;7(2):635-74

14. Kang JW, Nam D, Kim KH, Huh J-E, Lee J-D. Effect of Gambisan on the Inhibition of Adipogenesis in 3T3-L1 Adipocytes. Evid-Based Compl Alt. 2013;2013:789067.10.1155/2013/789067.

15. Fang $\mathrm{K}$, Wu F, Chen G, Dong H, Li J, Zhao $Y$, et al. Diosgenin ameliorates palmitic acid-induced lipid accumulation via AMPK/ ACC/CPT-1A and SREBP-1c/FAS signaling pathways in LO2 cells. BMC complementary and alternative medicine. 2019;19(1):255.10.1186/s12906-019-2671-9.

16. Wolf Greenstein A, Majumdar N, Yang P, Subbaiah PV, Kineman RD, Cordoba-Chacon J. Hepatocyte-specific, PPARy-regulated mechanisms to promote steatosis in adult mice. The Journal of endocrinology. 2017;232(1):107-21.10.1530/joe-16-0447.

17. Zhong Q, Zhao S, Yu B, Wang X, Matyal R, Li Y, et al. High-density lipoprotein increases the uptake of oxidized low density lipoprotein via PPARy/CD36 pathway in inflammatory adipocytes. International Journal of Biological Sciences. 2015;11(3):256-65.10.7150/ijbs. 10258.

18. Vroegrijk IO, van Klinken JB, van Diepen JA, van den Berg SA, Febbraio M, Steinbusch LK, et al. CD36 is important for adipocyte recruitment and affects lipolysis. Obesity (Silver Spring). 2013;21(10):2037-45.10.1002/oby.20354.

19. Aranaz P, Navarro-Herrera D, Zabala M, Miguéliz I, Romo-Hualde A, López-Yoldi M, et al. Phenolic Compounds Inhibit 3T3-L1 Adipogenesis Depending on the Stage of Differentiation and Their Binding Affinity to PPARy. Molecules (Basel, Switzerland). 2019;24(6):1045.10.3390/molecules24061045.

20. Choi I, Park $Y$, Choi H, Lee EH. Anti-adipogenic activity of rutin in 3T3-L1 cells and mice fed with high-fat diet. BioFactors (Oxford, England). 2006;26(4):273-81.10.1002/biof.5520260405.

21. Jiang $Y$, Ding S, Li F, Zhang C, Sun-Waterhouse D, Chen Y, et al Effects of (+)-catechin on the differentiation and lipid metabolism of 3T3-L1 adipocytes. Journal of Functional Foods. 2019;62:103558. https://doi.org/10.1016/j.jff.2019.103558. 


\section{GRAPHICAL ABSTRACT}

\section{Aporosa villosa stem extract \\ (95\% ethanol)}

$\otimes$

Lipid accumulation

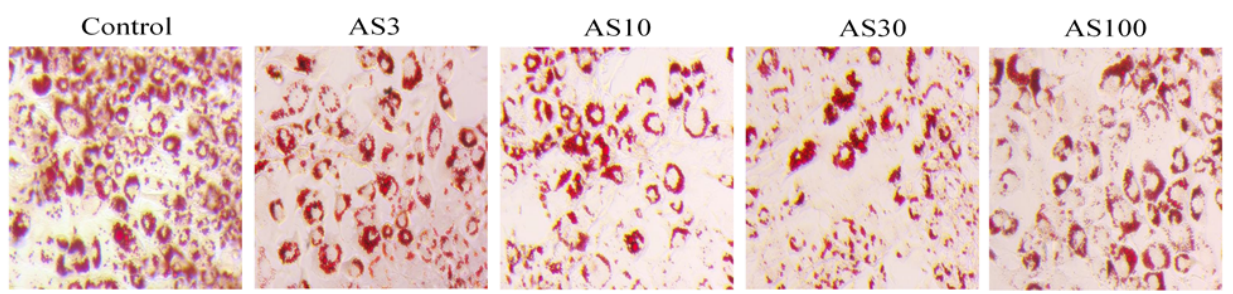

$\otimes$

\section{Adipogenic genes}

A

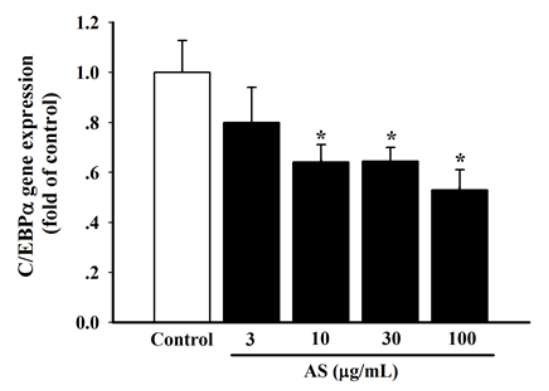

D

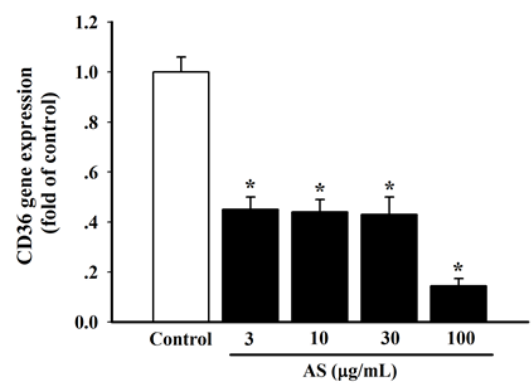

B

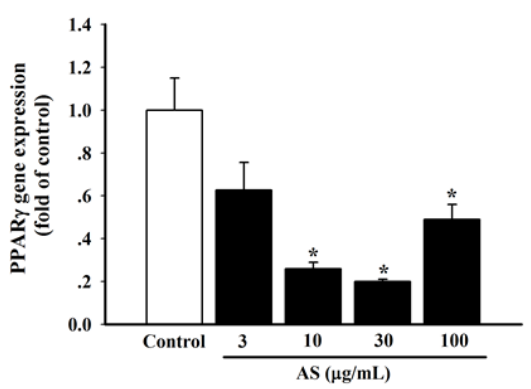

$\mathbf{E}$

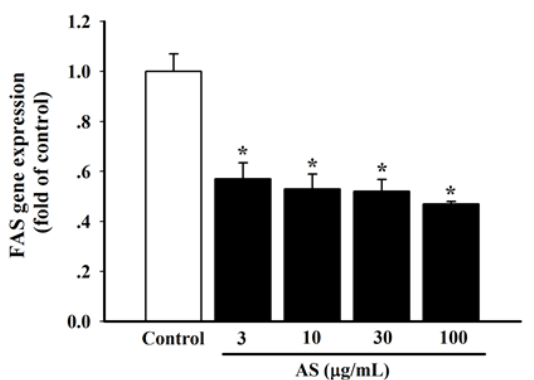

C

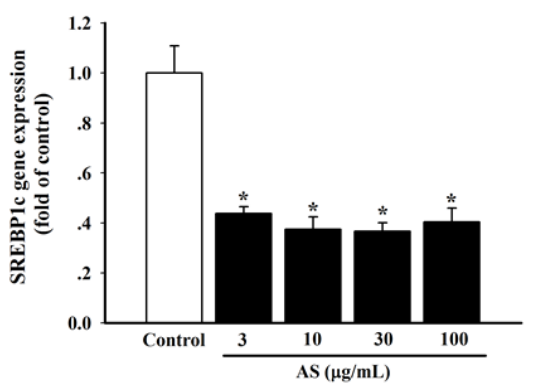

F

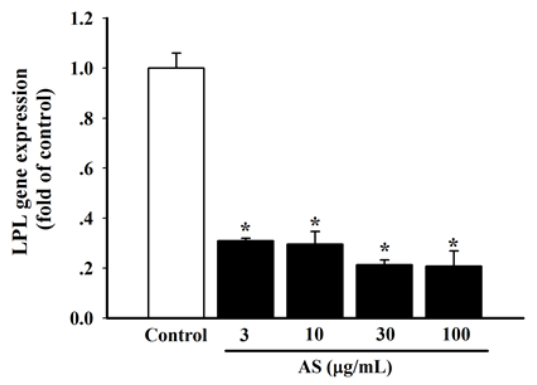




\section{ABOUT AUTHORS}

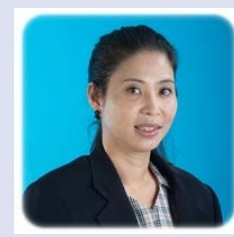

Urarat Nanna

Lecturer at the Department of Preclinical Science, Faculty of Medicine, Thammasat University

Scientific interests: pharmacological activity of medicinal plants

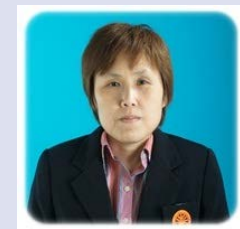

Linda Chularojmontri

Lecturer at the Department of Preclinical Science, Faculty of Medicine, Thammasat University Scientific interests: cardiovascular research, antioxidative effects of Thai medicinal plants, skin model

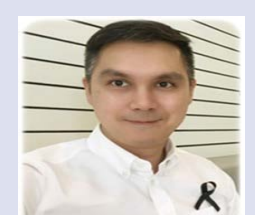

Pholawat Tingpej

Lecturer at the Department of Preclinical Science, Faculty of Medicine, Thammasat University Scientific interests: bacterial biofilm formation, biofilm decontamination strategies, bacterial pathogenesis and virulence factors, antimicrobial resistance prevalence and mechanisms

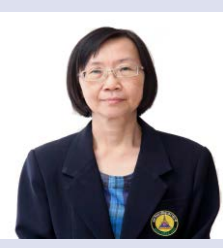

Rawiwun Kaewamatawong

Lecturer at the Faculty of Pharmaceutical Sciences, Ubon Ratchathani University

Scientific interests: phytochemistry, quality control of phytomaterials and products

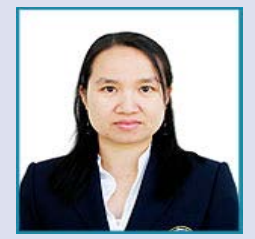

\section{Sudarat Homhual}

Lecturer at the Faculty of Pharmaceutical Sciences, Ubon Ratchathani University

Scientific interests: identification and standardization of herbal medicine, structure elucidation of compound by using spectroscopy technique, biological study of compound

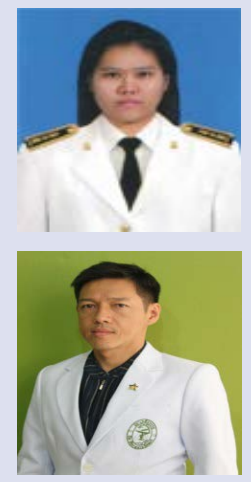

Wanwisa Suwannaloet

Lecturer at the Faculty of Medicine, Ubon Ratchathani University Scientific interests: pharmacological activity of medicinal plants, chondrogenesis study

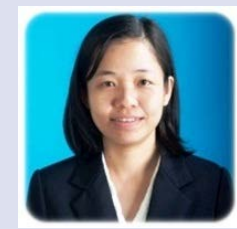

Thanes Fuangfoo

Lecturer at the Department of Pharmacology, College of Pharmacy, Rangsit University,

Scientific interests: phytochemistry

Jarinyaporn Naowaboot

Lecturer at the Department of Preclinical Science, Faculty of Medicine, Thammasat University Scientific interests: medicinal plants and metabolic syndrome

Cite this article: Nanna U, Chularojmontri L, Tingpej P, Kaewamatawong R, Homhual S, Suwannaloet W, et al. Effect of Aporosa villosa Stem Ethanolic Extract on Adipogenesis in 3T3-L1 Adipocytes. Pharmacogn J. 2021;13(6): 1422-1427. 